\title{
Dynamic modelling and optimal hierarchical control of a multiple-effect evaporator - superconcentrator plant
}

\author{
P. Gil ${ }^{1}$, H. Duarte-Ramos ${ }^{1}$, A. Dourado Correia ${ }^{2}$ \\ 1) Grupo de Engenharia Sistémica
}

Departamento de Engenharia Electrotécnica, Universidade Nova de Lisboa, Quinta da Torre - 2825 Monte da Caparica, Portugal. Tel: $+35112957787 / 2954464$. Fax: $+35112954461 / 2940965$. e-mail: psgemail.fct.unl.pt (P. Gil)

\section{2) CISUC - Centro de Informática e Sistemas}

Departamento de Engenharia Informática, Universidade de Coimbra, Largo Marquęs de Pombal - 3000 Coimbra, Portugal. Tel: +351397000000/7000006. Fax: +35139701266. e-mail:adouradolgemini.ci.uc.pt

\begin{abstract}
This paper presents new dynamic nonlinear mathematical models for a long tube vertical evaporator and for a plate-type falling film concentrator. Simulation results for a real evaporation system comprising 6 evaporators and one three-section concentrator are presented. In order to prevent from unacceptable deviations in outlet black liquor concentration due to measurable disturbances in weak black liquor, an optimal hierarchical infinite time linear regulator is designed.
\end{abstract}

\section{Keywords}

Evaporator, concentrator, modelling, simulation, hierarchical control.

\section{INTRODUCTION}

In both economics and environmental issues of wood pulping industry, it is essential that the spent chemicals from the cooking process be recovered for reuse. The very first step in the 
recovery cycle is to concentrate by an evaporation process the weak black liquor leaving the digesters. For good combustion performance and smooth operation of the boiler, it is quite important that solids content of strong black liquor be permanently high and, simultaneously, steady.

The present paper proposes new mathematical nonlinear models, at unsteady state operation, for a long tube vertical evaporator (LTV) and for a plate-type falling film concentrator, on the basis of fundamentals of heat transfer. In both models, the evaluation of heat transfer rate takes into account the flow regimes outside and inside the evaporator tubes and concentrator plates.

To investigate the feasibility of hierarchical control methodology for regulating black liquor concentration leaving the evaporation plant, it is formulated and implemented an optimal infinite time linear regulator within a two-level structure.

\section{MATHEMATICAL MODELLING}

\subsection{Long Tube Vertical Evaporator}

In a LTV evaporator (Fig. 1.a) the liquor enters the main liquor box at the bottom of the system, rises through the tubes and leaves out with higher solids content. In this path, the liquor is heated by the condensing steam located outside the tubes. At the same time, the static head liquor above the tube decreases and thus, at some point along the tube, the liquor starts to boil. When preheater or afterheater sections are incorporated, the liquor is previously heated before entering the respective evaporating section or the main liquor box of next effect.

\subsubsection{Modelling of a Single LTV Evaporator}

For the purposes of its modelling, the LTV evaporator with afterheater section is broken up into the following three parts: main liquor box, heating body including vapour space and afterheater section. Each one of these subsystems is delimited by a control volume and transient balances are written for total mass, solute and energy, taking into account some simplifying assumptions.

This approach leads to the following system of three nonlinear differential equations (Gil, 1995): black liquor concentration and temperature rates at the tube inlet and black liquor concentration rate at the exit plus one nonlinear algebraic equation describing the temperature gain in the afterheater section, as follows

$$
\begin{aligned}
& \frac{\mathrm{d} S_{L, i t}}{\mathrm{~d} t}=\dot{m}_{L, i r} \frac{S_{L, i d}-S_{L, i t}}{V_{r} \rho_{L, i t}} \\
& \frac{\mathrm{d} T_{L, i t}}{\mathrm{~d} t}=\left(\frac{\dot{m}_{L, i t}}{V \rho_{L, i t}}\right)\left[\left(h_{L, i r}-h_{L, i t}\right)-\left(S_{L, i r}-S_{L, i t}\right) \frac{\partial h_{L, i t}}{\partial t}\right]\left(\frac{\partial h_{L, i t}}{\partial T_{L, i t}}\right)^{-1}
\end{aligned}
$$


$\frac{\mathrm{d} S_{L, o t}}{\mathrm{~d} t}=\frac{2}{M_{L, t}}\left[\dot{m}_{L, t i} S_{L, t i}-\xi(\cdot)-\frac{\left(\frac{\partial h_{L, o t}}{\partial S_{L, o t}}\right)\left(\dot{m}_{L, i t} S_{L, t i t}-\xi(\cdot)\right)+\dot{m}_{L, i t}\left(h_{v a p, o t}-h_{L, i t}\right)-\dot{Q}+\gamma(\cdot)}{h_{v a p, o t}-h_{L, o t}+S_{L, o t} \frac{\partial h_{L, o t}}{\partial S_{L, o t}}} S_{L, o t}\right]$

$T_{L, O A f t}=\frac{\dot{Q}_{A f t}}{\dot{m}_{L, i A f t} c p_{L, i A f t}}+T_{L, i A f t}$

with

$\xi(\cdot)=\frac{1}{2} M_{L, t} \dot{m}_{L, i r} \frac{S_{L, i r}-S_{L, i t}}{\rho_{L, i t} V} \quad \gamma(\cdot)=\frac{M_{L, t}}{2}\left(\frac{\mathrm{d} h_{L, i t}}{\mathrm{~d} t}\right)$

As the above equations show, the mathematical model for the LTV evaporator is characterised by a strong interdependence on the descriptive main liquor box variables. In addition, as it was expected, main liquor box dynamics has a relevant influence on the heating section dynamics, without any reciprocity.

\subsubsection{Heat Transfer Rate in the Heating Section}

In most classical models found in literature, e.g. Niemi and Koistinen (1972), heat transfer rate in the heating section is determined assuming a constant overall heat transfer coefficient or evaluated according some specific empirical expressions. In our approach instead, since the overall heat transfer coefficient is a local parameter, the evaluation of heat transfer rate in heating section is based on a cylindrical discretization of the interface (see Equation 6). The evaluation of local heat transfer coefficient takes into account liquor flow pattern (bubbly, slug, churn, annular or foaming) and condensate flow regime (laminar or turbulent). Moreover, in each section the overall heat transfer coefficient and liquor temperature are supposed uniform and the axial heat flux is assumed negligible, so that

$\dot{Q}=\pi D \Delta l \sum_{k=1}^{N}\left[\bar{U}_{k}\left(T_{\text {vap }}-T_{L, k}\right)\right]$

where

$\bar{U}_{k}=\left[\frac{r_{t, i}}{r_{t, i}} \frac{1}{\bar{h}_{c o n d, k}}+\frac{r_{t, i}}{K_{I}} \ln \frac{r_{t, i}}{r_{I, i}}+\frac{r_{t, i}}{K_{t}} \ln \frac{r_{t, e}}{r_{t, i}}+\frac{r_{t, i}}{r_{t, e}} \frac{1}{\bar{h}_{c o n v, k}}\right]^{-1}$

Relationships for evaluating black liquor heat transfer coefficients can be found, for instance, in Olauson (1981).

\subsection{Plate - Type Falling Film Concentrator}

Plate-type falling film concentrator (Fig. 1.b) comprises, basically, a liquor distribution system, heating plates, vapour body, entrainment separator system for evaporated vapour and a 
collecting box. In this system, the heating fluid (steam) flows vertically upward inside the heating elements, while the liquor is distributed from the top over the plates and flows downward to the collecting liquor box.

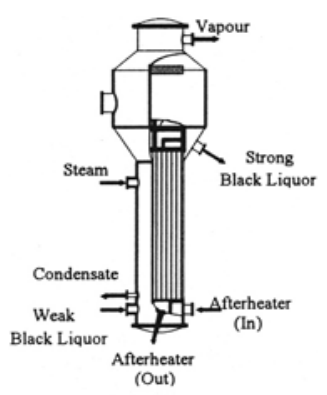

a)

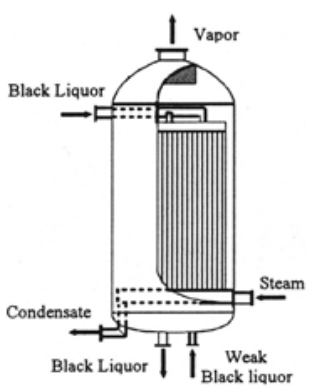

b)

Figure 1 a) Long tube vertical evaporator; b) Plate-type falling film concentrator.

\subsubsection{Modelling of a Single Plate-Type Falling Film Concentrator}

For modelling purposes, the plate-type concentrator comprises the following parts: bank of heating plates, distribution (top) and collecting (bottom) boxes. For each subsystem, energy and mass balance equations are written, assuming some symplifying assumptions. Mathematical expressions describing the concentrator dynamics are given bellow (Gil, 1995).

$$
\begin{aligned}
& \frac{\mathrm{d} S_{L, o p}}{\mathrm{~d} t}=\frac{2}{M_{L, p}}\left[\dot{m}_{L, i p} S_{L, i p}-\frac{S_{L, o p} \dot{m}_{L, i p}}{h_{L, o p}-h_{v a p, o}-S_{L, o p} \frac{\partial h_{L, o p}}{\partial S_{L, o p}}}\left(h_{L, i p}-h_{v a p, o}-S_{L, o p} \frac{\partial h_{L, o p}}{\partial S_{L N, o p}}+\dot{Q}\right)\right] \\
& \frac{\mathrm{d} S_{L, B}}{\mathrm{~d} t}=\frac{\dot{m}_{L, o p}\left(S_{L, o p}-S_{L, B}\right)}{V_{B} \rho_{L, B}} \\
& \frac{\mathrm{d} T_{L, B}}{\mathrm{~d} t}=\left(\frac{\dot{m}_{L, o p}}{V_{B} \rho_{L, B}}\right)\left[h_{L, o p}-h_{L, B}-\frac{\partial h_{L, B}}{\partial S_{L, B}}\left(S_{L, o p}-S_{L, B}\right)\right]\left(\frac{\partial h_{L, B}}{\partial T_{L, B}}\right)^{-1}
\end{aligned}
$$

Equation (8) represents black liquor concentration rate at the plates exit, while equations $(9$, 10) describe, respectively, black liquor concentration and temperature rates within the collecting box.

\subsubsection{Heat Transfer Rate in the Heating Plates}

For evaluating heat transfer rate in the vertical heating plates, by the same reasons mentioned for LTV evaporators, the transfer interface is discretized applying a rectangular mesh. In each 
elemental section, overall heat transfer coefficient and flow temperature are taken to be constants and heat transfer among adjacent sections is considered negligible. Local overall heat transfer coefficients are evaluated taking into account flow regimes (laminar or turbulent) inside and outside heating elements. The relationship for evaluating heat transfer rate is given bellow.

$$
\dot{Q}=N_{p} b \Delta \ell \sum_{k=1}^{N}\left[\bar{U}_{k}\left(T_{v a p}-T_{L, k}\right)\right]
$$

where

$$
\bar{U}_{k}=\left[\frac{1}{\bar{h}_{c o n d . k}}+\frac{\Delta e_{p}}{K_{p}}+\frac{\Delta e_{1}}{K_{l}}+\frac{1}{\bar{h}_{c o n v, k}}\right]^{-1}
$$

Relationships for evaluating $\bar{h}_{\text {cond }}$, and $\bar{h}_{\text {conv }}$ can be found, for instance, in Gil (1995).

\section{EVAPORATION PLANT SIMULATION}

Black liquor evaporation plant (Fig. 2) consists of six LTV evaporators, incorporating afterheater section, excepting for IIA effect, and one three-section falling film plate-type concentrator. Weak black liquor is fed in parallel to the IV (70\%) and V (30\%), while fresh steam is fed to the concentrator.

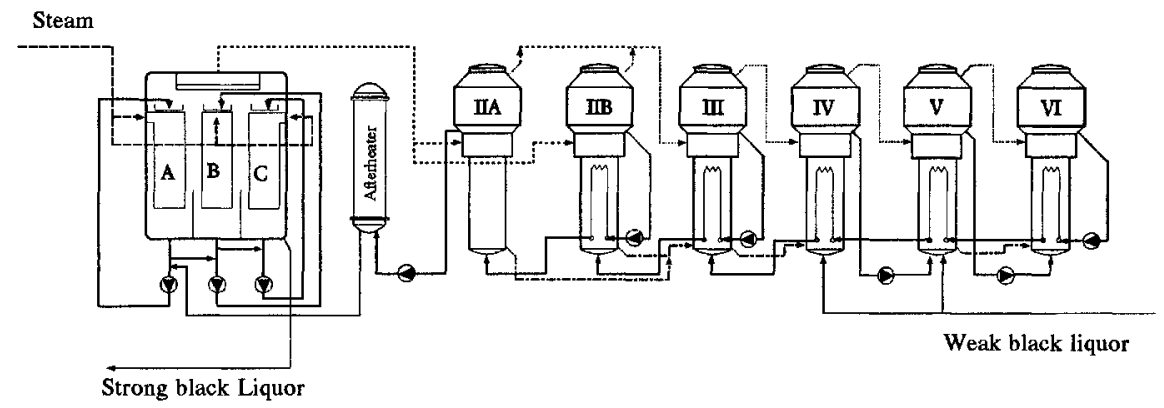

Figure 2 Simplified flow diagram for the evaporation plant.

Based on the proposed nonlinear models, a partially linear model, obtained by Taylor expansion, was derived for simulating the evaporation plant dynamics. In figure 3 it is plotted the transient response to a step change of $10 \%$ in weak black liquor concentration.

For that disturbance, the system shows a slight drop in the concentration of black liquor leaving the concentrator. This reduction is mainly explained by the influence of black liquor concentration upon heat transfer rate. The increase in concentration causes a reduction in heat transfer rate which impose a decreasing in concentration gain. Such a drop leads to an augmentation of black liquor mass flux to the forward stages, thus contributing for a gradual black liquor gain decrease in these evaporators. 

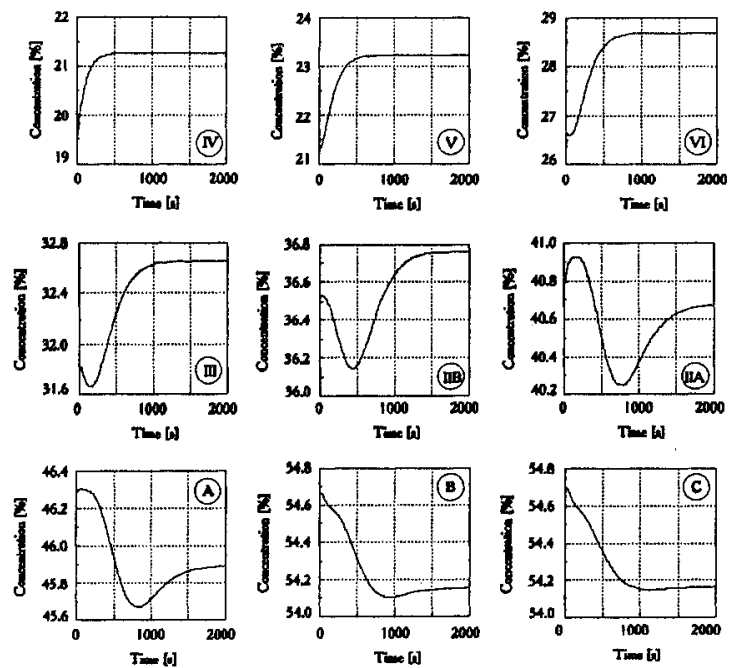

Figure 3 Evaporation system time response.

\section{CONTROL STRATEGY}

For eliminating the influence of measurable disturbances in weak black liquor upon solids content of black liquor leaving the evaporation plant, an optimal hierarchical infinite continuous time linear regulator is implemented. This regulator is synthesised according the interaction prediction method proposed by Takahara (Jamshidi, 1983) and taking fresh steam pressure in each concentrator section as manipulated variable.

\subsection{Problem Formulation}

The optimisation problem for $N$ interconnected dynamical system, with state vectors $x_{1}, \ldots, x_{\mathrm{N}}$, may be stated as follows: Find the admissible local control vectors $\boldsymbol{u}_{1}, \ldots, \boldsymbol{u}_{\mathrm{N}}$, which minimises the quadratic cost function (13), under restrictions (14), Titli (1978).

$$
\begin{aligned}
& J(u(t))=\frac{1}{2} \sum_{i=1}^{N}\left\{\left\|\boldsymbol{x}_{\mathrm{i}}\left(t_{\mathrm{f}}\right)\right\|_{P_{i}}^{2}+\int_{0}^{\infty}\left[\left\|\boldsymbol{x}_{\mathrm{i}}(t)\right\|_{Q_{i}}^{2}+\left\|\boldsymbol{u}_{\mathrm{i}}(t)\right\|_{R_{i}}^{2}\right] \mathrm{d} t\right\} \\
& \dot{\boldsymbol{x}}_{i}(t)=\boldsymbol{A}_{i} \boldsymbol{x}_{i}(t)+\boldsymbol{B}_{i} \boldsymbol{u}_{i}(t)+\boldsymbol{F}_{i} \boldsymbol{w}_{i}(t)+C_{i} \boldsymbol{z}_{i}(t) ; \boldsymbol{z}_{i}(t)=\sum_{\substack{j=1 \\
j \neq i}}^{N}\left(\boldsymbol{L}_{i j} \boldsymbol{x}_{j}(t)+\boldsymbol{M}_{i j} \boldsymbol{u}_{j}(t)\right)
\end{aligned}
$$

where $\boldsymbol{P}_{i}, \boldsymbol{Q}_{i}$ are real symmetric positive semi-definite matrices, $\boldsymbol{R}_{i}$ is real symmetric positive definite matrix and $\|\boldsymbol{b}\|_{L}^{2}=\boldsymbol{b}^{\mathrm{T}} \boldsymbol{L} \boldsymbol{b} . \boldsymbol{A}_{i}, \boldsymbol{B}_{i}, \boldsymbol{F}_{i}$ and $\boldsymbol{C}_{i}$ are, respectively, the state, input, disturbance and interaction matrices, whilst $\boldsymbol{L}_{i j}$ and $\boldsymbol{M}_{i j}$ are the state and control interaction matrices between the $i$ th and $j$ th subsystems. This problem can be solved by first introducing a set of Lagrange multipliers $\lambda_{i}(t)$ and costate vectors $p_{i}(t)$ to the cost function integrand, forming the Lagrangian (15). 


$$
\begin{aligned}
L(\cdot)= & \sum_{i=1}^{N}\left\{\frac{1}{2}\left\|x_{i}\left(t_{\mathrm{f}}\right)\right\|_{P_{i}}^{2}+\int_{0}^{\infty}\left[\frac{1}{2}\left(\left\|x_{i}(t)\right\|_{Q_{i}}^{2}+\left\|u_{i}(t)\right\|_{R_{i}}^{2}\right)+\lambda_{i}(t)\left(z_{i}(t)-\sum_{j=1}^{N}\left(L_{i j} x_{i j}(t)+M_{i j} u_{i j}(t)\right)\right)\right.\right. \\
& \left.\left.+p_{i}(t)\left(-\dot{x}_{i}(t)+A_{i} x_{i}(t)+B_{i} u_{i}(t)+F_{i} w_{i}(t)+C_{i} z_{i}(t)\right)\right] \mathrm{d} t\right\}
\end{aligned}
$$

For a given coordination vector $[\lambda, z]$, equation (15) is additively separable and can be decomposed into $N$ independent sub-Lagrangians. Each subsystem's Lagrangian is then minimised independently to the others. This procedure, which constitutes the first level of the hierarchical structure, is based on the necessary conditions for local optimality, Athans and Falb (1966). At the second level, where the solutions of all first-level subsystems are known, new coordenation vectors are iteratively evaluated according to (16).

$$
\left[\begin{array}{l}
\lambda_{i}(t) \\
z_{i}(t)
\end{array}\right]^{(k+1)}=\left[\begin{array}{c}
-C_{i}^{\mathrm{T}} \boldsymbol{p}_{i}(t) \\
\sum_{j=1}^{N}\left(\boldsymbol{L}_{i j} \boldsymbol{x}_{i j}+\boldsymbol{M}_{i j} \boldsymbol{u}_{i j}\right)
\end{array}\right]^{(k)}
$$

For infinite time regulation, when $\boldsymbol{P}_{i}=0$ and $\boldsymbol{A}_{i}, \boldsymbol{B}_{i}, \boldsymbol{R}_{i}$ and $\boldsymbol{Q}_{i}$, are constant matrices the solution of differential Riccati equation leads to a constant matrix. This means that the implementation of each local optimal controller consists of two parts: one of which is a local feedback fixed amplifier and the other is a pre-filter to determine the optimal driving function from disturbances and interactions.

\subsection{Hierarchical Optimal Regulation of Evaporation Plant}

In figure $4 . \mathrm{a}$ it is plotted the optimal path of black liquor solids content at the concentrator outlet, for a step disturbance of $+10 \%$ in weak black concentration. As can be seen, the proposed control scheme reduces significantly the transient deviation from the set-point concentration (59.5\%) and provides an adequate steady state solids content. Convergence to the optimal control took place in just 6 iterations of the second level (Fig. 4.b) which took 104 seconds to execute in a PC486 DX/2-66MHz, assuming the inicial values of coordination vector as $[00]^{\mathrm{T}}$ and an error adjoint vector of $10^{-12}$.

\section{CONCLUSIONS}

In this paper it was proposed new dynamic nonlinear mathematical models for a long tube vertical evaporator and for a plate-type falling film concentrator. Evaluation of heat transfer rate takes into account flow regimes outside and inside the evaporator tubes and concentrator plates.

For controling a black liquor evaporation plant comprising six evaporators and one threesection falling film concentrator, it was designed an optimal two-level hierarchical infinite time linear regulator, using the interaction prediction method. Computed results show the effectiveness of this control strategy. 


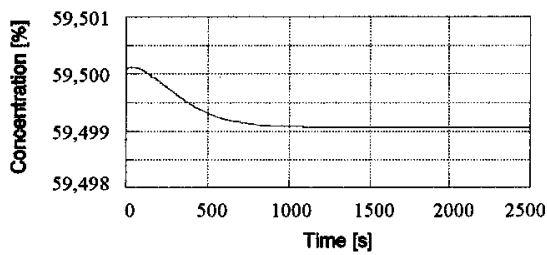

a)

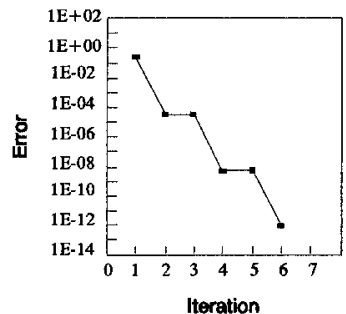

b)

Figure 4 a) Regulated evaporation plant time response for a step disturbance of $+10 \%$ in weak black liquor concentration; b) Adjoint trajectory error vs iterations.

\section{Symbols}

$h$, enthalpy [J/kg]

$\dot{m}$, mass flux $\left[\mathrm{kg} / \mathrm{m}^{3}\right]$

$K$, thermal conductivity $\left[\mathrm{W} / \mathrm{m}^{2 \circ} \mathrm{C}\right]$

$M$, mass [kg]

$N$, number of elements

$r$, radius [m]

$S$, solids level $[\mathrm{kg} / \mathrm{kg}]$

$T$, temperature $\left[{ }^{\circ} \mathrm{C}\right]$

$t$, time [s]

$U$, overall heat transfer coefficient $\left[\mathrm{W} / \mathrm{m}^{2 \circ} \mathrm{C}\right]$

$V$, volume $\left[\mathrm{m}^{3}\right]$

$\rho$, density $\left[\mathrm{kg} / \mathrm{m}^{3}\right]$

\section{Subscripts}

Cond, condensation

Conv, convection

$L$, liquor

$i$, inlet

$o$, outlet

$r$, main liquor box

$t$, tube

$A f t$, afterheater

$B$, collecting box

I, incrustation

Aknowledgments: This work is carried on in cooperation with PORTUCEL-Viana (Ings. J.L. Amaral and D. Trancoso).

\section{REFERENCES}

Athans, M. and Falb, P (1966) Optimal Control: An Introduction to the Theory and Its Applications. McGraw Hill, New York.

Gil, P. (1995) Modelizaçăo Matemática e Controlo Hierárquico Contínuo de uma Cadeia de Evaporaçăo. M.S. Thesis, University of Coimbra, Coimbra, Portugal.

Jamshidi, M. (1983) Large Scale Systems: Modeling and Control. North-Holland, New York.

Niemi, A., Hartikainen, E. and Koistinen, R (1974) Dynamics and Control of Multiple-Effect Evaporator and Drum Washer Plants. Proc. 4th IFAC/IFIP International Conference on Digital Computer Applications to Process Control, 503-19.

Olauson, L. (1981) Heat Transfer in Climbing-Film Evaporators. Svensk Papperstidning, 84, 61-71.

Titli, A. and Singh, M. (1978) Decomposition Optimization and Control. Pergamon Press, Oxford. 